\title{
TECTÔNICA CISALHANTE NA EVOLUÇÃO DO RIFT DO RECÔNCAVO - TUCANO - JATOBÁ
}

\author{
EDSON JOSE MILANI ${ }^{*}$
}

\begin{abstract}
On the basis of fracture pattern analysis and two-dimensional gravimetric crustal models a tentative mechanism is proposed for the tectonic evolution of the Recôncavo-Tucano-Jatobá rift. The direction of active stress during the basin evolution defined from observations of differential crustal thinning was related to a $\mathrm{N} 60 \mathrm{OW}$ regional extension. It seems that reactivated major $\mathrm{NW}$ trending Precambriam fault zones have played an important role during the Early Cretaceous tectonic phase in the studied area, acting as transform faults subparallel to the extensional stress direction. The most significant zones along which lateral movement is characterized are the Mata-Catu trend, the Itapicuru fault system and the Vaza-Barris high. The rift is markedly asymmetric whith faults downtrow and subsidence increasing toward one side; crustal thickness decreases in the same direction. The importance of transform movement in the evolution of the Recôncavo-Tucano-Jatobá rift is analogous to that recognized in other similar basins of the world.
\end{abstract}

INTRODUÇÃo Situado na Região Nordeste do Brasil, o rift do Recôncavo-Tucano-Jatobá está implantado numa direção geral $\mathrm{N}-\mathrm{S}$, com cerca de $450 \mathrm{~km}$ de comprimento e $100 \mathrm{~km}$ de largura máxima; em seu extremo norte, mostra forte deflexão para ENE, direção na qual se prolonga por mais $150 \mathrm{~km}$ constituindo a fossa de Jatobá (Fig.1).

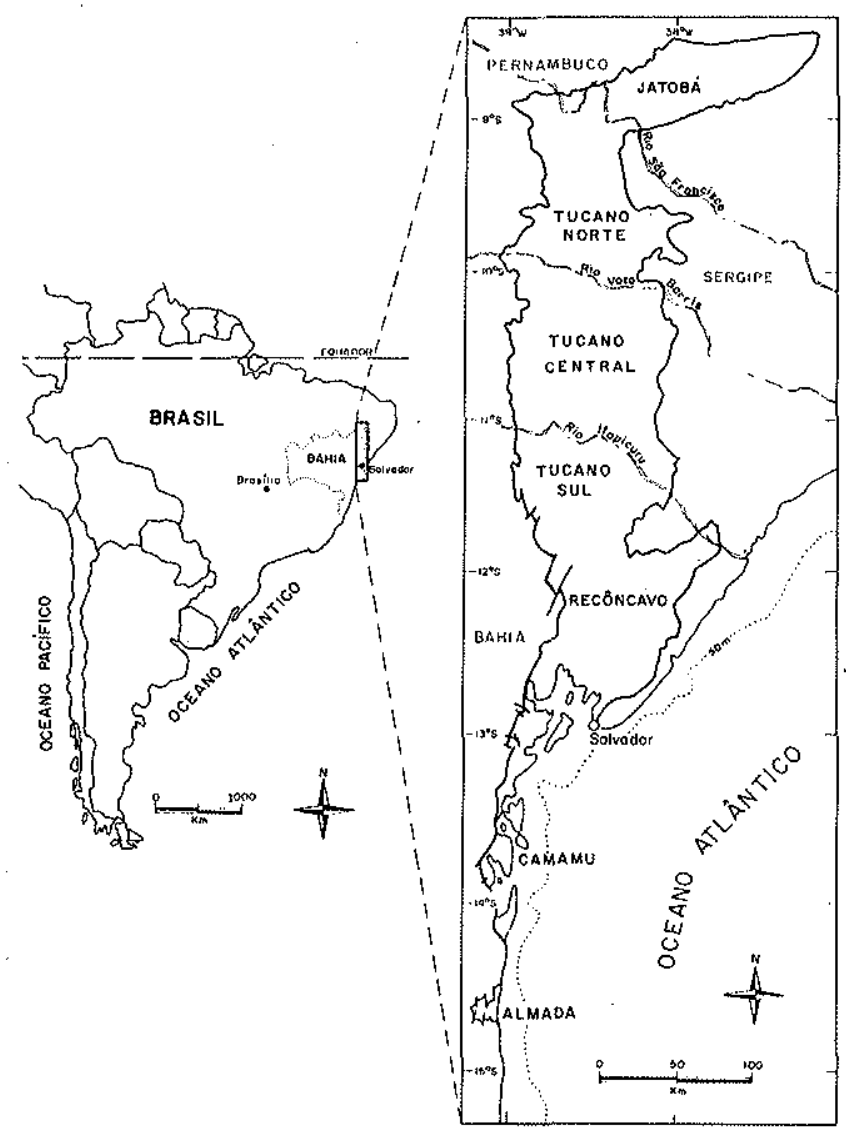

Figura 1-Mapa de situação.

Apesar de se configurar como uma feição tectônica contínua, este conjünto de bacias falhadas não é conhecido,. geologicamente, de modo homogêneo; apenas seu terço sul, formado pelas fossas do Recôncavo e Tucano Sul, é coberto por sísmica de reflexão com malha bastante densa na primeira.

Do paralelo de 11 oS para o norte, o arcabouço do rift é conhecido apenas por meio de gravimetria, sísmica de refração e 15 poços estratigráficos.

As interpretações estruturais clássicas desta área postulam duas fases principais de falhamento: uma no tempo Rio da Serra e outra pós-Buracica (Cretáceo Inferior), ambas tendo gerado falhas normais dentro de um modelo de rift extensional.

Este trabalho apresenta um modelo al ternativo, que considera a influência de zonas de cisalhamento de direção geral NW-SE na evolução do rift, com base em dados sísmicos, gravimétricos e de subsuperfície.

GEOLOGIA REGIONAL O rift do Recôncavo-Tucano -Jatobá é uma feição ruptural eocretácica que se encontra implantado sobre terrenos de natureza e idade diversas, constituintes da geologia pretérita da região (Fig. 2); as zonas de fraqueza desses elementos geotectònicos antigos parecem ter sido decisivas no estabelecimento do padrão estrutural do arcabouço dessa fossa.

Durante os estágios iniciais de ruptura crustal, este rift evoluiu concomitantemente às bacias que hoje constituem a margem leste brasileira. Posteriormente, a fase marinha da história evolutiva das bacias marginais não encontraria correspondência nestes grabens uma vez que seu desenvolvimento tecto-sedimentar cessou no andar Alagoas (Cretáceo Inferior).

O embasamento dessas fossa foi estudado por Cordani et al. (1984); as amostras rochosas provenientes de poços demonstram que o substrato do rift corresponde ao contex to geológico das diferentes províncias geotectônicas em que está inserido.

Desta forma, a direção geral do rift, N-S, parece ser herança da principal linha estrutural do Cráton do São Francisco nesta área, segundo a qual se alinham greenstone belts nos terrenos granítico-gnáissico-migmatíticos. 


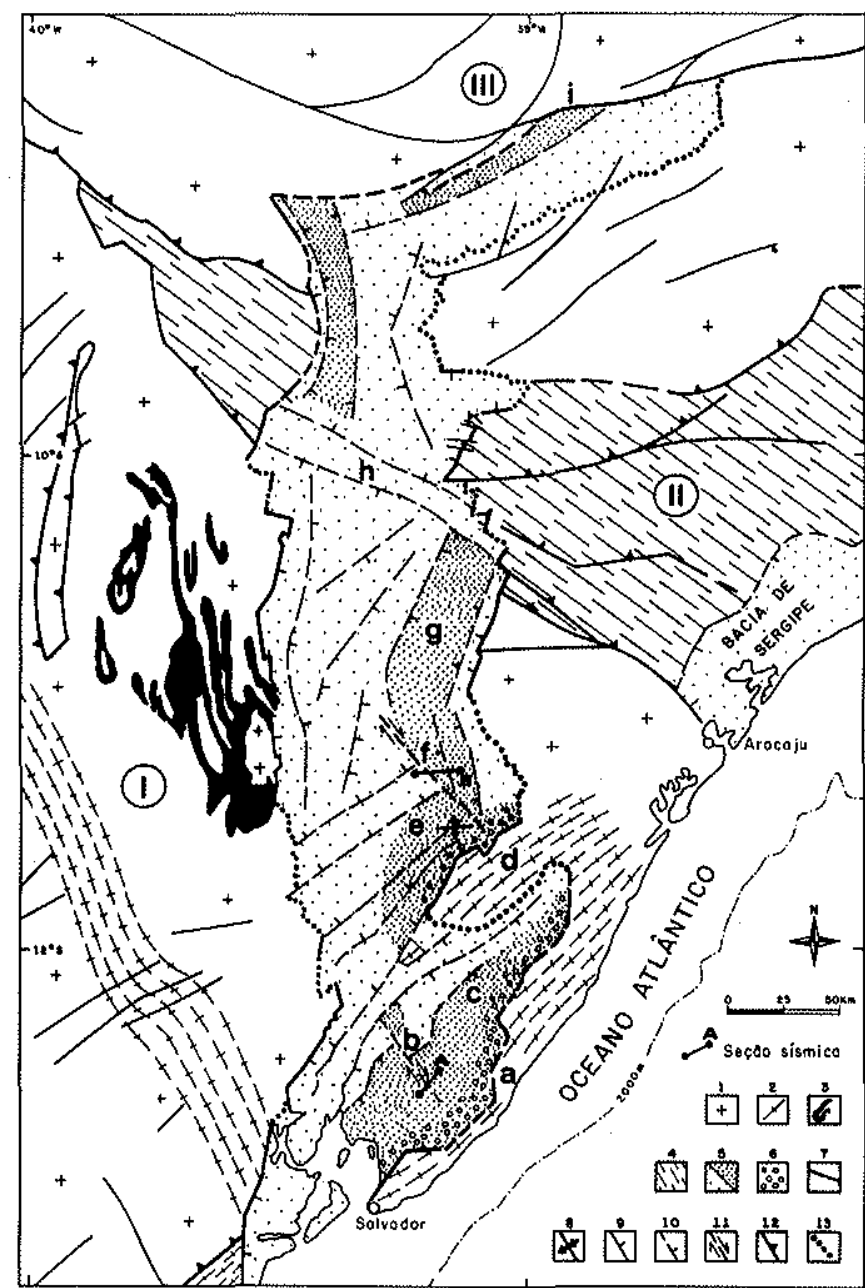

Figura 2 - Geologia regional e arcabouço estrutural do rift. Provincias pré -cambrianas: $\quad l$. Cráton do São Francisco; II. Sistema de Dobramentos Sergipano; III. Maciço de Pernambuco-Alagoas. Feições tectônicas do rift; a) Alto de Salva dor; b) Falha de Mata-Catu; c) Calha Central do Recôncavo; d) Alto de Aporá; e)Baixo de Olindina-Inhambupe; f) Falha do Itapicuru; g) Baixo do Sitio do Quinto; h) Arco do Vaza-Barris; i) Falha de Ibimirim. Legenda: 1 terrenos granitico-gnáissico-migmatiticos; 2 . cinturäo granulitico; 3 , greenstone belts; 4. metassedimentos do Sistema de Dobramento Sergipano; 5. Bacias Sedimentares Cretácias (pontos adensados nas áreas mais profundas); 6. Flanglomerados cretácicos; 7. Falhamentos de movimento näo-especificado (Proterozóico superior); 8. Eixo de anticlinal; 9. Falhamentos normais (Cretáceo); 10. Falhamentos normais definidos sismicamente (Cretáceo); 11. Falhamentos transcorrentes definidos sismicamente (Cretáceo); 12. Falhas de empurrão (Proterozóico superior); 13. Contato litológico

A influência de zonas de fraqueza antigas no desenvolvimento de feições tectônicas mais jovens tem sido estudada em áreas de rift; McConnell (1972) definiu os principais traços estruturais com influência no rifteamento do leste africano e interpretou-os como descontinuidades fundamentais da litosfera, com tendência a freqüentes rejuvenescimentos desde o Arqueano, pelo que os dominou lineamentos profundos perenes.

$\mathrm{Na}$ área estudada, a interferência de lineamentos antigos na evolução da fossa é bastante clara em algumas porções enquanto, em outras, o rift, corta quase transversalmente as feiçōes estruturais pré-cambrianas.

$\mathrm{O}$ graben do Recôncavo obedece à direção do ramo NE da faixa granulítica Atlântica, bifurcada à altura do paralelo de 130 S (Cordani et al. 1984). Esta faixa caracteriza-se por rochas intensamente foliadas com grandes zonas de milonitização, que geram alinhamentos visíveis em imagens de radar na escala de 1:250.000. Esta foliação, como zona de fraqueza do corpo rochoso, ditou a direção principal de ocorrência de falhamentos normais no Recôncavo e no Tucano Sul, qual seja, N200-40oE.

A Bacia de Jatobá, implantada sobre o maciço granítico-gnáissico de Pernambuco-Alagoas, é fortemente condicionada pelas desconstinuidades deste; e o strike estrutural da fossa é regido pelos grandes falhamentos de direção ENE que o segmentam, lineamentos estes de caráter polifásico e que, sob o campo de tensões cretácico, apresentaram rejeito gravitacional, originando o graben.

O Sistema de Dobramentos Sergipano, faixa móvel do Proterozóico Superior com vergència para o Cráton do São Francisco e strike geral NW-SE, é outro elemento de marcante influência na evolução do rift em questão. Os grandes falhamentos associados à orogenia desta faixa estabeleceram descontinuidades crustais pronunciadas, reativadas pelo evento distensivo cretácico.

MORFOLOGIA ESTRUTURAL DO RIFT A Bacia do Recôncavo, que constitui a porção meridional do rift, é um meio-graben cujo embasamento mergulha progressivamente no sentido SE, cujo limite é o Alto de Salvador, do qual se separa pela falha de mesmo nome (Fig. 2).

Seu arcabouço por duas direções principais: $\mathrm{N} 30^{\circ} \mathrm{E}$, coincidente com as falhas normais ao longo do strike da fossa; e N40 $\mathrm{W}$, representada por grandes elementos diastróficos transversais, que Netto et al (1984) interpretam como falhamentos transcorrentes de idade burácica segmentando a bacia em três compartimentos - sul, central e nordeste, sendo a Falha de Mata-Catu a principal delas.

Separada do Recôncavo pelo Alto de Aporá, aparece a Bacia do Tucano Sul, cujo arcabouço é definido por falhas de direção geral $\mathrm{N} 30^{\circ} \mathrm{E}$. Nesta bacia predominam falhamentos antitéticos em relação ao depocentro da fossa, com mergulho geral do embasamento no sentido $\mathrm{SE}$, enquanto no Recôncavo as falhas são predominantemente sintéticas.

Um grande falhamento transversal, cujo traço coincide com o do Rio Itapicuru (Fig. 2), segmenta o rift naquela área e separa o Tucano Sul do Central. Esta zona é subparalela à Falha de Mata-Catu na vizinha Bacia do Recôncavo.

As fossas do Tucano Central, Tucano Norte e Jatobá são menos conhecidas. Entretanto, é notável a mudança no sen. tido de mergulho do embasamento a partir do Arco do Vaza-Barris (Fig. 2); ao norte desta feição, o depocentro da bacia está instalado junto à borda oeste, ao contrário do que ocorre no restante do rift.

A Bacia de Jatobá, no extremo setentrional do rift, consiste num meio-graben cujo embasamento mergulha para Norte; seu depocentro associa-se à Falha de Ibimirim, trecho de um extenso lineamento do Pré-Cambriano orientado na direção ENE, que apresentou um rejeito vertical cretácico de cerca de $4.000 \mathrm{~m}$.

DEFORMAÇÃO CRUSTAL DO RIFTEAMENTO - CAMPO DE TENSÕES O desenvolvimento de um sistema de 
bacias do tipo rift requer a atuação de um regime de esforços distensivo numa determinada região.

Este campo de tensões tende a deformar a litosfera na área afetada no sentido de the adelgaçar a espessura original num processo de extensão (McKenzie 1978).

Desta forma, os mecanismos de rifteamento dão origem a uma área com espessura crustal anômala em relação às regiōes vizinhas; o manto e a astenosfera, sob o rift, encontram-se mais próximos da superfície. A interação desses elementos, entre os quais existe um significativo contraste de densidade, gera anomalias gravimétricas características.

Modelagem gravimétrica do rift do Recôncavo-Tucano-Jatobá Quatro perfis cruzando o rift foram modelados a partir de dados gravimétricos extraídos do mapa Bouguer da bacia (Petrobrás/RPBA/Direx 1970), mostrado na figura 3.

0 método de modelamento gravimétrico consiste num programa computacional, desenvolvido por Talwani et al. (1959), que calcula as componentes vertical e horizontal da gravidade gerada por corpos bidimensionais mediante aproximações a polígonos ideais.

A partir de modelos geológicos em duas dimensões, esta técnica fornece o correspondente perfil gravimétrico (sintético) que, comparado ao perfil observado, permite estimar-se o grau de precisão contido no modelo proposto.

No processamento dos perfis, foram consideradas as seguintes densidades para os corpos geológicos envolvidos: sedimentos (areno-argilosos, cretácicos) $=2,45 \mathrm{~g} / \mathrm{cm}^{3}$; sedimentos paleozóicos de Jatobá $=2,58 \mathrm{~g} / \mathrm{cm}^{3}$; conglomerados sintectônicos $=2,62 \mathrm{~g} / \mathrm{cm}^{3}$; embasamento $($ crosta) $=2,80$ $\mathrm{g} / \mathrm{cm}^{3} ; \mathrm{e}$ manto $=3,30 \mathrm{~g} / \mathrm{cm}^{3}$.

A seção $A-A^{\prime}$ (Fig. 4) mostra a Bacia de Jatobá num corte: transversal à fossa, na direção SSW-NNE. Nota-se a forte assimetria da bacia, a borda NNE sendo representada pela Falha de Ibimirim; e o embasamento mergulha progressivamente, a partir da borda sul, contra este falhamento.

Aspecto semelhante apresenta a seção $B-B^{\prime}$ (Fig. 5), que corta a Bacia do Tucano Central na direção E-W. Este perfil cruza o Baixo do Sítio do Quinto, área mais profunda do rift, com uma amplitude gravimétrica de $150 \mathrm{mGal} \mathrm{em}$ relação à borda leste da fossa; e sua profundidade ultrapassa os $10.000 \mathrm{~m}$.

$\mathrm{O}$ perfil $C$ - $C^{\prime}$ (Fig. 6) mostra um corte $\mathrm{NW}-\mathrm{SE}$, que abrange as bacias do Tucano Sul e Recôncavo, separadas pelo Alto de Aporá.

Um aspecto notável, comum às três seções, é a falta de coincidência dos mínimos gravimétricos com as áreas mais profundas das bacias, fato marcante principalmente em $B-B^{\prime}$ e $C$-C'. Destaca-se também a disparidade entre os valores de anomalia Bouguer de uma das bordas da fossa em relação à outra, ao longo de todos os perfis.

Tais fatos levam a admitir a influência de massas mais densas, em posição intra-embasamento, que atenuam a anomalia negativa gerada pela bacia.

Assim, as curvas gravimétricas apresentadas foram adequadamente modeladas considerando-se um "relevo" ao nível do manto, produto do estiramento crustal diferencial no rifteamento.

A associação desses "diápiros" do manto com os falhamentos de grande rejeito e com as áreas mais profundas da fossa, adjacentes a estes, destaca a relação genética existente entre as falhas normais, as áreas de maior subsidência e as porções em que a crosta sofreu um maior grau de afinamen.

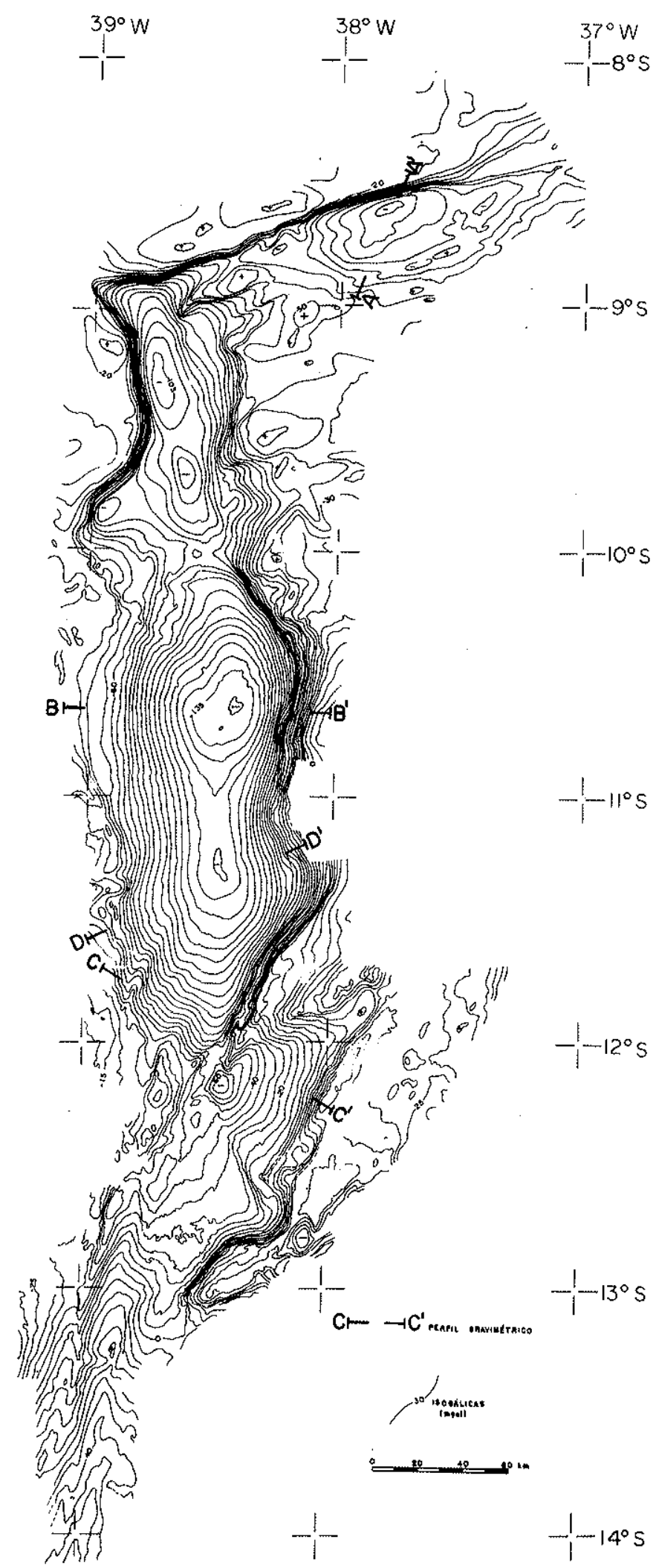

Figura 3 - Mapa Bouguer do rift com a posição das modelagens gravimétricas elaboradas

to sob o rift, fenômenos estes produzidos pelo esforço tracional gerador da bacia. 


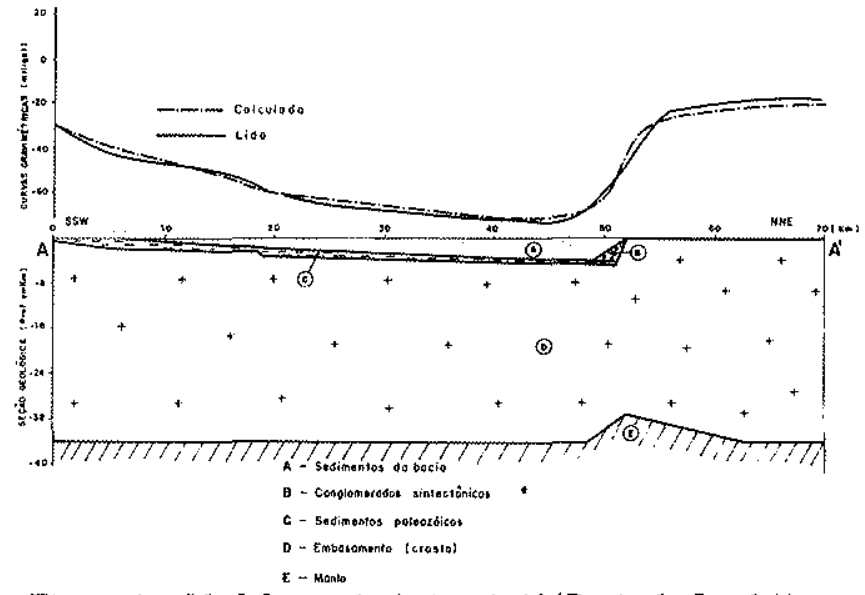

Figura 4-Modelo gravimétrico A-A' (Bacia de Jatobá)

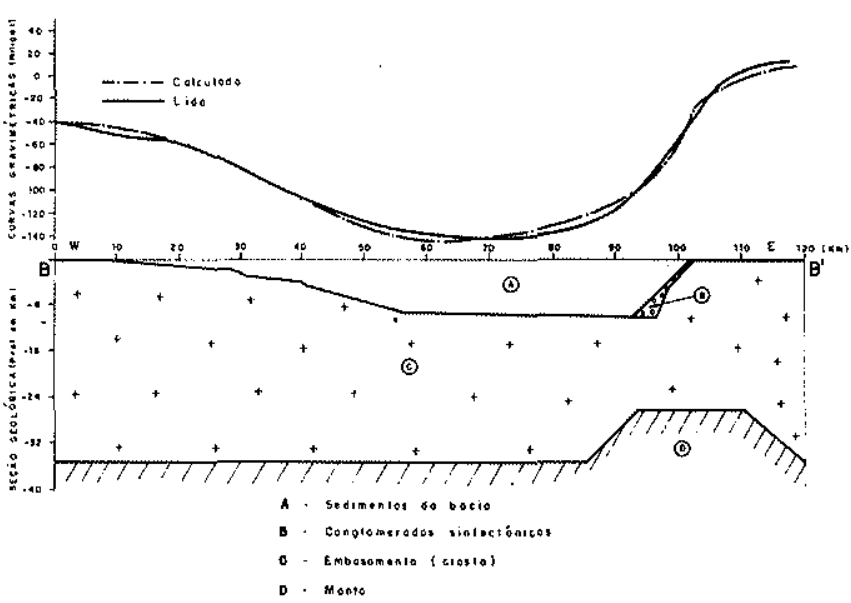

Figura 5 - Modelo gravimétrico B-B' (Bacia do Tucano Central)

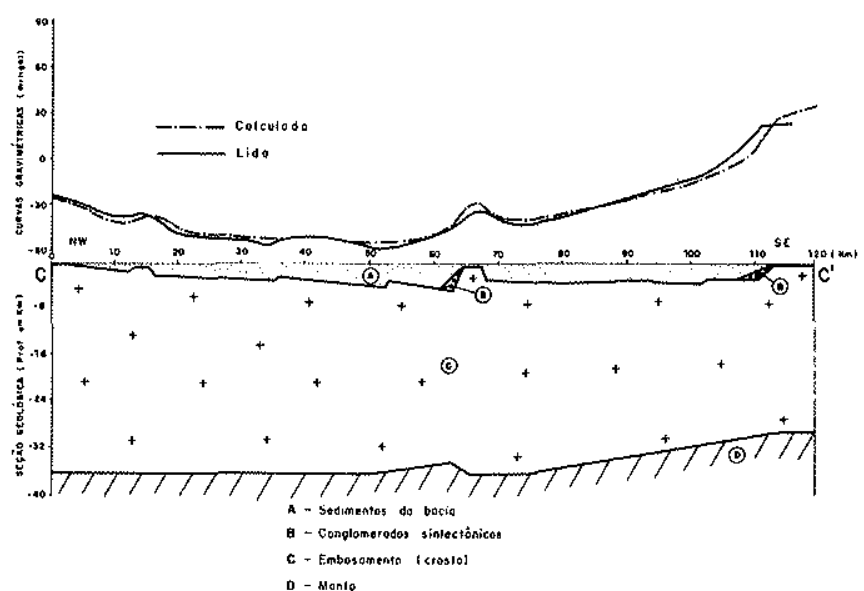

Figura 6 - Modelo gravimétrico C-C'(bacias do Tucano Sul e Recôncavol

0 fato de, em áreas extensionais, encontrar-se o trend principal de falhamentos orientado perpendicularmente à extensão regional posiciona o eixo de máximo esforço tracional, à época da ruptura, na direção N600W; esta orientação coincide com a do campo de tensões deduzido em escala continental (Fig. 7). Nota-se, na reconstituição pré-deriva de Rabinowitz \& LaBrecque (1979), que o limite entre os dois continentes, à exceção da faixa pontilhada, dá-se ao longo de uma linha praticamente reta, orientada a $\mathrm{N} 30^{\circ} \mathrm{E}$, direção esta paralela à dos efeitos extensionais no rift do Recôncavo-Tucano-Jatobá.

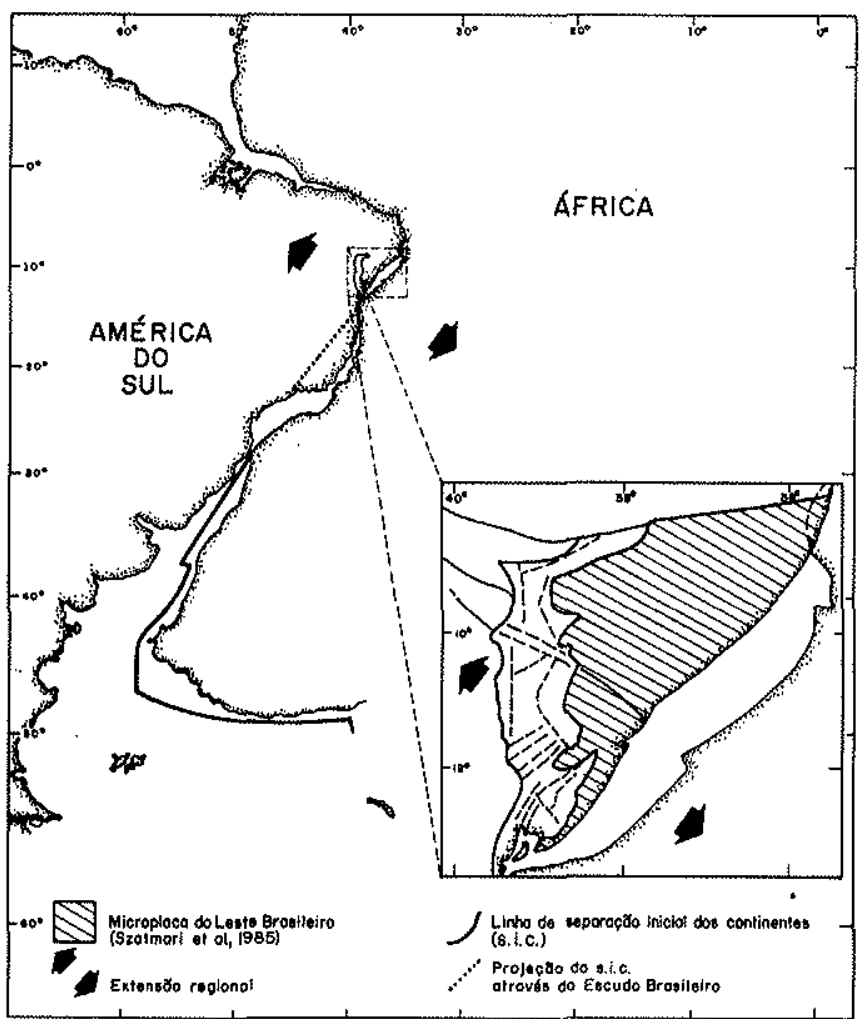

Figura 7 - Reconstituição pré-deriva da posição dos continentes africano e sul-americano (este em sua posição atual) com a orientação do esforço distensivo cretácico; no detalhe, o mesmo campo de tensões na área do rift. Modificado de Rabinowitz \& LaBrecque (1979)

Em virtude de sua orientação NE-SW, o perfil $D-D^{\prime}$ (Fig. 8) mostra características distintas em relação aos anteriormente comentados; neste, a curva de anomalias gravimétricas expressa fielmente a morfologia bacinal que, neste corte, é relativamente simétrica. Considerando-se estar esta serão orientada perpendicularmente à direção de afinamento crustal, não seriam esperados efeitos gravimétricos produzidos por variações na espessura crustal, uma vez que ela é, nesta direção, relativamente uniforme.

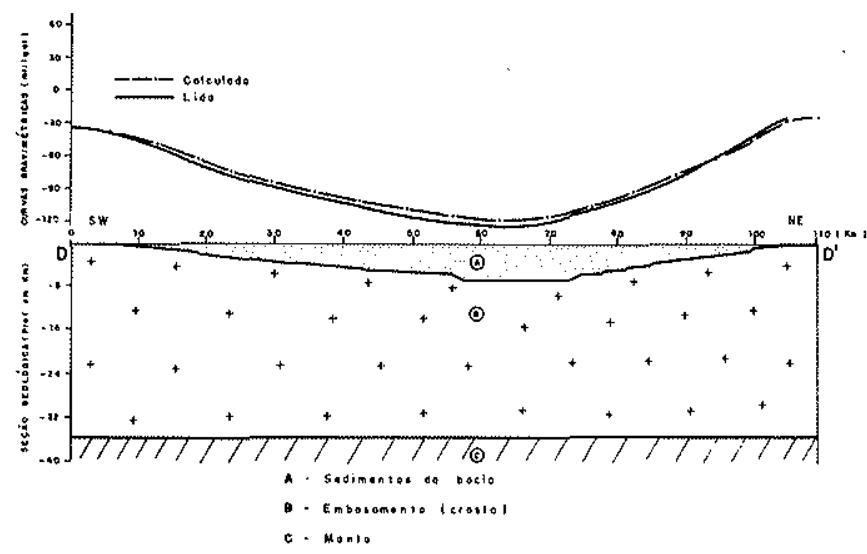

Figura 8 - Modelo gravimétrico D-D' (Bacia do Tucano Sul) 
MODELO EVOLUTIVO A evolução do rift do Recôncavo-Tucano-Jatobá está ligada ao campo de tensões que originou a margem leste brasileira e culminou por separar definitivamente os continentes africano e sul-americano (Fig. 7).

Dentro desse contexto, a fossa em questão constitui-se num ramo abortado do rift principal e sua história evolutiva guarda íntima relação à movimentação, no Cretáceo Inferior, da Microplaca do Leste Brasileiro (Szatmari et al 1985). O conjunto de bacias do Recôncavo-Tucano-Jatobá constitui a borda extensional da microplaca e foi, durante algum tempo, o sítio principal de separação entre África e América do Sul naquela área.

A posterior mudança do eixo do rifteamento para sua atual posição, na margem continental (Bacia de Sergipe-Ala. goas), culminaria por consolidar a microplaca ao continente sul-americano, encerrando a história evolutiva da fossa baiana.

A geometria do rift do Recôncavo Tucano-Jatobá sugere, à primeira vista, ser este o produ to de um esforço distensivo de orientação $\mathrm{E}-\mathrm{W}$, uma vez que se configura como uma megafratura $\mathrm{N}-\mathrm{S}$.

Entretanto a análise do arcabouço desta fossa revela alguns aspectos significativos, por exemplo, a distribuição dos depocentros, que não acompanham a direção regional $\mathrm{N}-\mathrm{S}$. Tanto a calha central do Recôncavo quanto o Baixo de Olindina-Inhambupe no Tucano Sul e o Baixo do Sítio do Quinto no Tucano Central (Fig. 2) consistem em feições restritas às sub-bacias em que estão contidos e apresentam orientação geral nordeste.

A direção de afinamento crustal, NW-SE, também não é compatível com um esforço $\mathrm{E}-\mathrm{W}$ bem como o trend principal de falhamentos, de orientação SW-NE, no arcabouço do rift.

Desta forma, o esforço distensivo cretácico, orientado a N60oW, utilizou as descontinuidades pré-existentes na região (Fig. 9-I) para originar uma série de meio-grabens posicionados en échelon segundo a grande zona de fraqueza $\mathrm{N}-\mathrm{S}$, associada ao Cratón do São Francisco. Essas depressões seriam, durante toda a história evolutiva do rift, seus centros principais de subsidência (Fig. 9-II).

Oldenburg \& Brune (1975) realizaram experimentos em que demonstram a evolução de fossas numa situação mecanicamente semelhante a esta; a propagação de fraturas paralelas cria, em suas terminações, zonas de overlap, onde se desenvolvem tensões cisalhantes; tais áreas coincidem com as porções hachuradas da figura 9.II.

Com o progressivo desenvolvimento da fossa, geram-se falhas transcorrentes que ligam os meio-grabens até então isolados (Fig. 9-III) e estabelecem a configuração final do rift.

A presença de deslocamentos horizontais nestas bacias foi aventada pela primeira vez por Melo (1970) baseando-se em mapas de isópacas. Netto et al. (1984), após mapeamento detalhado, reconheceram o papel das transcorrências na compartimentação tectônica da Bacia do Recôncavo.

Regionalmente, as falhas transcorrentes nesta área orientam-se na direção aproximada $\mathrm{N} 40^{\circ} \mathrm{W}$.

A Falha de Mata-Catu, no Recôncavo, apresenta o maior número de evidências de movimento horizontal: repetição de camadas e inversão estratigráfica em poços perfurados próximos a ela; deslocamento de linhas de charneira e de falhas mais antigas; arqueamento de refletores devido a um

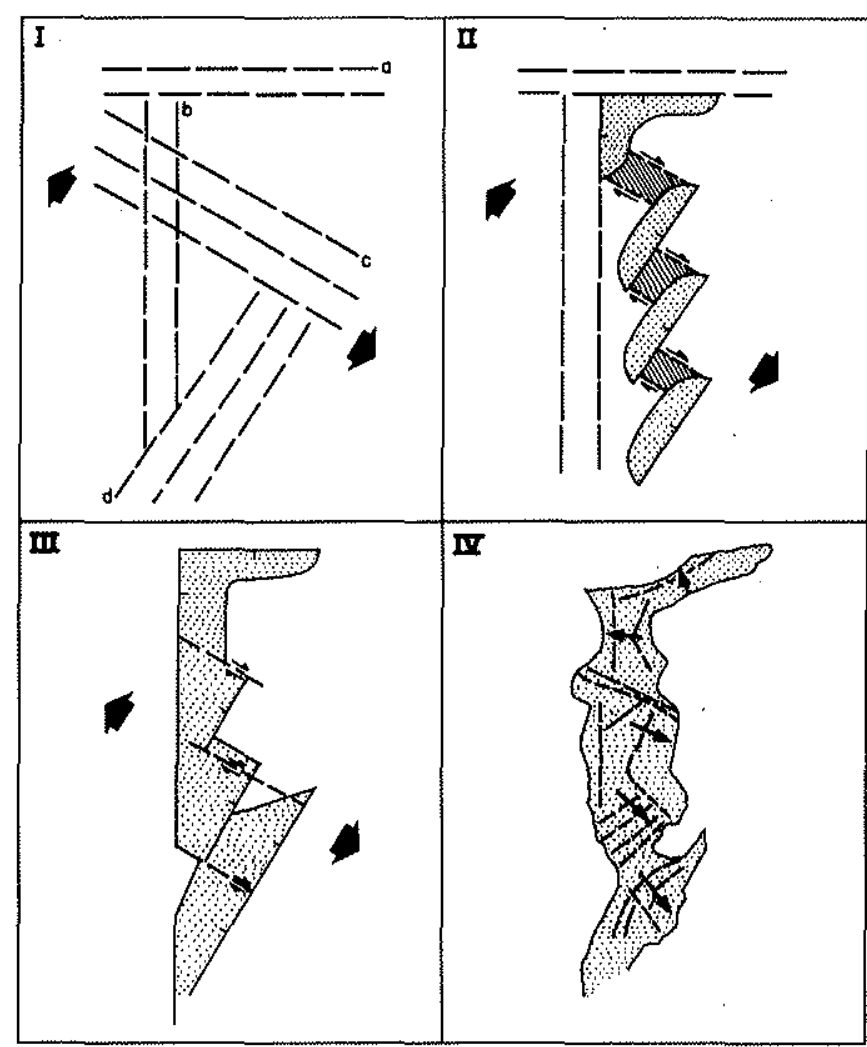

Figura 9 - Evolução tectônica esquemática do rift do Recôncavo-Tucano-Jatobá. I. Principais descontinuidades précambrianas na região: a) Macico de Pernambuco-Alagoas; b) Cráton do Säo Franscisco; c) Sistema de Dobramentos Sergipano; d) Cinturão granulitico Atlântico. As setas representam a orientação do campo distensivo cretácico. II. Usando zonas de fraqueza crustais, aparece uma série de meio-grabens e definem-se grandes falhas normais em uma de suas bordas; nas regiōes de superposição lateral (hachuradas), de senvolvem-se tensões cisalhantes. III. Os semi-grabens alargam-se por flexuramentos nas bordas e aparecem falhas transcorrentes cortando todo o pacote sedimentar até então depositado, agora ativas até o final da evolução do rift. IV. Configuração atual; as setas pequenas indicam o sentido de mergulho do embasamento em cada sub-bacia

cárater localmente transpressional (Fig. 10); e o "efeito da tesoura", ou seja a mudança da relação bloco alto-bloco baixo ao longo do traço da falha.

$\mathrm{Na}$ Bacia do Tucano Sul, a Falha do Itapicuru apresenta características sísmicas de falhamento transcorrente com o desenvolvimento de uma "estrutura-em-flor" negativa (Fig. 11). $\mathrm{Na}$ área de Crisópolis, adjacente à Falha do Itapicuru, desenvolve-se um grande arqueamento, provavelmente inserido no contexto transcorrente desta zona.

Embora desprovido de evidências diretas, o Arco do Vaza-Barris, por seu paralelismo às zonas transcorrentes de Mata-Catu e do Itapicuru e por seu tectonismo pronunciado (Ghignone 1979), pode ser interpretado como uma terceira grande zona de cisalhamento e segmentação transversal do rift.

Esses elementos de deslocamento lateral desempenham o papel de falhas transformantes, qual seja, conectam segmentos deslocados do eixo do rift. Desta maneira, o esforço tracional de ruptura refletiu-se ao longo de direçð̃es sub per- 


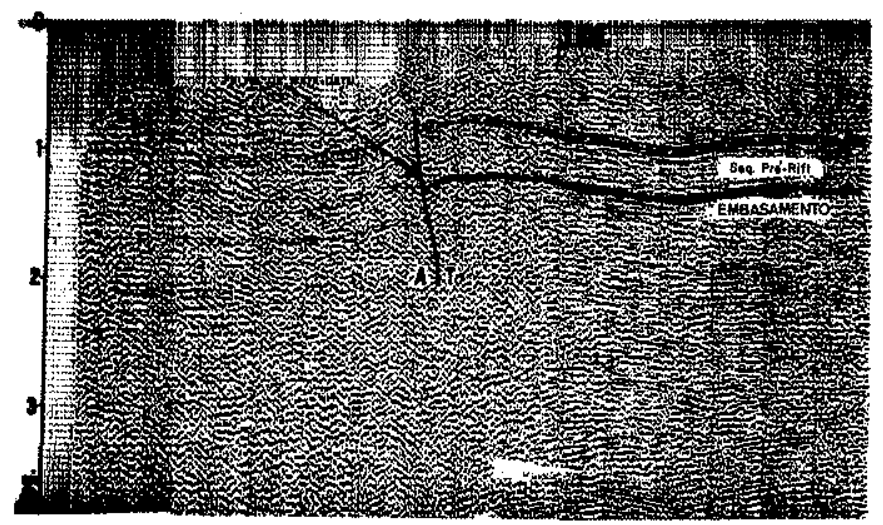

Figura 10 - Seção sísmica A, área de Mata-Catu. O encurvamento dos refletores é devido, provavelmente, à transgressão ao longo do contato entre os blocos convergentes da falha transcorrente dextral ( $A$, away, $T$, toward)

pendiculares à extensão regional por meio de subsidência pronunciada e estiramento crustal, ao mesmo tempo que blocos crustais se movimentaram lateralmente entre si, ao longo de linhas estruturais sub paralelas à aplicaçāo do esforço, com componentes verticais variáveis associadas.

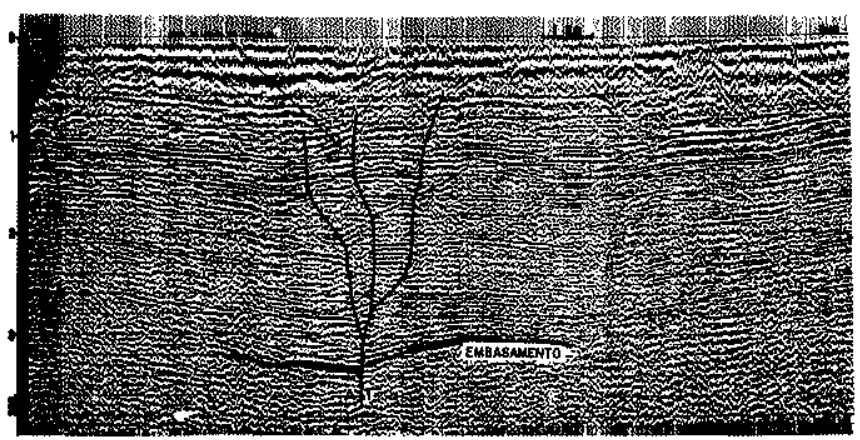

Figura 11 - Seção sismica B mostrando a zona de falha do Itapicuru, com o desenvolvimento de uma "estrutura-emflor" negativa. Trata-se de um falhamento transcorrente dextral $(A$, away; $T$, toward)

Agradecimentos $\quad \mathrm{O}$ autor é grato ao Dr. Peter Szatmari, pela orientação e revisão do manuscrito; aos colegas João Cláudio J. Conceição e Marcos C. Lana, pelas proveitosas discussōes; aos técnicos do Setor de Métodos Potenciais da Petrobrás, pelo auxílio nas modelagens gravimétricas; ao géologo Guilherme $\mathrm{O}$. Estrella, pelo incentivo; e à Petroleo Brasileiro S.A. Petrobrás, por permitir a publicação deste trabalho.

\section{REFERENNCIAS BIBLIOGRÁFICAS}

CORDANI, U.G.; NEVES, B.B.B.; FUCK, R.A.; PORTO, R.; THOMAZ FILHO, A.; CUNHA, F.M.B. - 1984 - Estudo preliminar de integração do Pré-Cambriano com os eventos tectôni$\cos$ das bacias sedimentares brasileiras. Ciência-Técnica-Petróleo, Seção: Exploração de Petróleo n.o 15,70 p.

GHIGNONE, J.I. - 1979 - Geologia dos sedimentos fanerozóicos do Estado da Bahia. In: INDA, H.A.V. (ed.), Geologia e recursos minerais do Estado da Bahia: textos básicos n. ${ }^{\circ} 2$. Salvador, Sec. Min. da Bahia, p. 24-117.

McCONNELL, R.B. - 1972 - Geological development of the East African rift system. Bull. Geol. Soc. Am., 83:2549-2572.

MCKENZIE, D. - 1978 - Some remarks on the development of sedimentary basins. Earth and Planetary Science Letters, 40:25-32.

MELO, U. - 1970 - A possivel ocorrência de falhas de deslocamento horizontal no Recôncavo. Petrobrás/RPBA/Setrin, relatório interno.

NETTO, A.S.T.; BRAGA, J.A.E.; BRUHN, C.H.L.; MAGNAVITA, L.P.; OLIVEIRA, J.J.; AGLE, H.M.; RIBEIRO, J.C. $-1984-$ Prospectos estratigráficos do Reconcavo. Petrobrás/Dexba, relatório interno.

OLDENBURG, D.W. \& BRUNE, J.N. - 1975 - An explanation for the orthogonality of ocean ridges and transform faults. $J$. Geoph. Research, 80:2575-2585.

PETROBRĀS/RBPA/DIREX - 1970 - Mapa Bouguer - Bacias Recôncavo, Tucano e Jatobá; escala 1:100.000. Salvador.

RABINOWITZ, P.D. \& LaBRECQUE, J, - 1979 - The Mesozoic South Atlantic ocean and the evolution of its continental margins, J. Geoph. Research, 84:5973-6002.

SZATMARI, P.; MILANI, E.J.; LANA, M.C.; CONCEIÇÃO, J.C.J.; LOBO, A.P. - 1985 - How South Atlantic rifting affects Brazilian oil reserves distribution. Oil and Gas Journal, 83(2):107-113.

TALWANI, M.; WORZEL, J.L.; LANDISMAN, M. - 1959 - Rapid gravity computations for two-dimensional bodies with application to the Mendocino submarine fracture zone. $J$. Geoph. Research, 64(1):49-59.
MANUSCRITO

Recebido em 20 de agosto de 1984 Revisão aceita em 30 de abril de 1986

“... o uso de uma teoria para o propósito de predizer algum evento específico é apenas outro aspecto de seu uṣo para o propósito de explicar tal evento". 